\title{
The influence mechanism of free gift promotion on purchase intention of gifts: A moderated mediation model
}

\author{
Wenguo Shen \\ Junzhi Xiang \\ Business School, Sun Yat-sen University, \\ Guangzhou, China
}

\section{Keywords}

Free gift promotion, transaction utility, purchase intention, brand value

\begin{abstract}
Previous research has examined the effects of free gift promotion on purchase intention of the main products, but its effects on purchase intention of products offered as gifts have been neglected. Based on the theory of transaction utility, this paper proposes a moderated mediation model, aiming to study the impact of free gift promotion on purchase intention of gifts and its internal mechanism. Two experiments are conducted to test the hypothesis. The results are presented as follows: Firstly, free gift promotion reduces purchase intention of gifts. Secondly, transaction utility of gifts has a complete mediating effect on the relationship between free gift promotion and purchase intention of gifts. Thirdly, brand value of main products moderates the negative impacts of free gift promotion on transaction utility of gift. Fourthly, brand value of main products also moderates the indirect impacts of free gift promotion on purchase intention of gifts via the mediating effect of transaction utility. This research not only enriches the literature of free gift promotion, but also provides managerial implications for marketing managers.
\end{abstract}

Corresponding author: Wenguo Shen

Email address for the corresponding author: Mnsshwg@mail.sysu.edu.cn

First submission received: 25 th February 2019

Revised submission received: $17^{\text {th }}$ March 2019

Accepted: 9th April 2019

\section{Acknowledgements}

The fund project, the National Natural Science Fund of China (\#71772186) and the National Natural Science Fund of Guangdong Province of China (\#2018A030313862)

\section{Introduction}

Free gift promotion is one of the main strategies for enterprises to lift sales of products. In cases of free gift promotion, the products given to consumers for free are called gifts, while the promoted ones are the main products. In order to improve the effects of free gift promotion, retailers are giving away branded products as gifts in free gift promotions. For example, consumers purchasing mobile phones on JD.com will get Yoobao power banks for free. Many manufacturers, in order to boost the overall sales of their products, are offering certain free products with purchase of other products many manufacturers, such as people who have bought Mi mobile phones will receive free Mi power banks.

Previous studies have shown that, the more appealing gifts are to consumers, the more the free gift promotions will contribute to the rising sales of main products (Harlam and Lodish, 2012). However, it is unknown whether purchase intention of these gifts will change, when they are sold as independent products after the promotions. Plenty of studies have analyzed the impacts of free gift promotion on purchase intention of main products, brand switching, and sales in both the short and long run (Chandon, Wansink and Laurent, 2000; Gilbert and Jackaria, 2002). Few of them explored how free gift promotions may influence purchase intention of gifts. As more and more branded products are playing the role of gifts, it is worth to study how purchase intention of these products may be impacted by free gift promotions when they are sold separately. This paper will study the impact of free gift promotion on purchase intention of gifts and its internal mechanism, based on the theory of transaction utility, and the contributions to theoretical advances and management implications is also discussed. 


\section{Theoretical Background \\ Transaction Utility}

Thaler (1985) puts forward the theory of transaction utility, postulating that in business transactions, the perceived utility of products can be divided into two types: acquisition utility and transaction utility. The former depends on the value of products received compared to their prices, while the latter depends solely on the perceived value of the deal per se, namely the difference between the selling price and the reference price expected by consumers. When consumers pay less than the reference price, the perceived financial savings would bring a sense of pleasure and satisfaction to consumers - this is how transaction utility works (Zhang and Xie, 2015). Thaler (1985) presents the theory with the following model:

$$
\mathrm{W}\left(\mathrm{z}, \mathrm{p}, \mathrm{p}^{*}\right)=\mathrm{v}(\overline{\mathrm{p}},-\mathrm{p})+\mathrm{v}\left(-\mathrm{p}:-\mathrm{p}^{*}\right)
$$

In this equation, $W\left(z, z, p^{*}\right)$ is the total utility from a purchase of products. $P$ is the selling price of product $z, \bar{p}$ is defined as the value equivalent of $z$, and $p^{*}$ stands for the expected price for $z$. In this way, $\mathrm{v}(\overline{\mathrm{p}},-\mathrm{p})$ is the acquisition utility, namely the net utility that accrues from the trade of $\mathrm{p}$ to obtain $\mathrm{z}$ (which is valued at $\overline{\mathrm{p}})$; $\mathrm{v}\left(-\mathrm{p}:-\mathrm{p}^{*}\right)$ is the transaction utility, which depends on the price an individual pays $(\mathrm{p})$ compared to some reference price $\left(\mathrm{p}^{*}\right)$ (Thaler, 1985).

Thaler (1985) states that the transaction utility of a product can be either positive or negative. When the selling price is higher than the expected price, the transaction utility is negative; otherwise, it is positive. The reference price of a product perceived by consumers is how much they normally expect to pay for it (Zhang and Xie, 2015), and it may be impacted by various factors, such as previous purchase experience, previous prices of the product (Kalyanaram, 1994; 1995), the variety of the product, sales promotions (Folkes, 2013), selling price of alternative products (Kalyanaram, 1995), and price variation trend of the product (Kalwani, Morrison and Chi, 2014).

Many researchers have studied the impacts of transaction utility on consumers' purchase decisions. Based on the statistics from retail stores, Winer (2007) finds out that evaluation of the transaction utility of coffee may significantly influence their purchase intention and brand choices for coffee。Urbany (1988) hold that, if the perceived transaction utility of a product can be lifted, consumers will be more likely to buy it.

\section{Value-Discounting Hypothesis in Free Gift Promotion}

Prior literature has shown that, sales promotions may not only influence purchase decisions, but also prompt consumers to speculate on the motivation of enterprises; meanwhile, their conclusions will serve as an important aid in their future decisions (Inman, Mcalister and Hoyer, 1990). Raghubir (2004) discusses the impact of gift promotion on the perceived price of gifts when they are offered as stand-alone products and proposes the value-discounting hypothesis. He finds that, by virtue of being offered as free gifts, consumers are willing to pay lesser for these products. It is also found that this effect may be moderated by (a) whether the price information of gifts is present to consumers, and (b) the value of the promoted products. According to the study, the price information of gifts presented by enterprises is usually an aid for consumers to make judgments about the value of gifts. The presence of price information of gifts should undermine the value-discounting effect. Raghubir also points out that, without knowing the value of gifts, consumers tend to compute the value of gifts based on the value of main products and a certain range of expectations about discount rates (e.g. $20 \%-40 \%$ ). They also believe that the main products with high value boast higher profit margins and are able to offer more costly gifts along with purchase. Hence, the value-discounting effect of gifts is weaker when they are offered along with purchase of higher-priced products as compared to lower-priced ones (Raghubir, 2004).

Brand Value of Main Products

Brand value is a core concept in brand management theories. Many scholars advocate viewing brand value from the perspective of consumers. In this sense, the value of a brand originates from consumer recognition for it, which depends on the impacts of previous brand marketing efforts on the psychology of consumers (Fan, 2000). Ke11er (1993) argues that brand value is established upon consumer perceptions of brand promotions, and these perceptions will give rise to the difference in their knowledge of various brands. Previous studies of free gift promotion have shown that the effect of free gift promotion on main products will be significantly moderated by their brand value (Mccarthy and Norris, 1999). Will 
the impacts of free gift promotion on purchase intention of gifts be moderated by the brand value of main products? It will be explored in the paper.

\section{Hypotheses \\ Free Gift Promotion and Transaction Utility}

As discussed before, free gift promotions will lower the expected price of gifts (Kamins, Folkes and Fedorikhin, 2009; Raghubir, 2004). According to the transaction utility theory, transaction utility is composed of the selling price and the expected price Thaler (1985). If the selling price of gifts remains the same, the transaction utility of gifts will decline.

H1: Free gift promotions reduces the transaction utility of gifts.

\section{The Mediating Effect of Transaction Utility}

Winer (2007) revealed that, transaction utility significantly influences purchase intention. Free gift promotion reduces the transaction utility of gifts, which will further undermine purchase intention of gifts. Lai, Doong and Yang (2006) found that the transaction utility in the most-probable case being most strongly correlated with the intention to join group buying. Hence, this paper holds that free gift promotions will decrease purchase intention of gifts via the mediating effect of transaction utility.

$\mathrm{H} 2$ : Free gift promotions decreases purchase intention of gifts.

H3: Transaction utility has a mediating effect between free gift promotions and purchase intention of gifts.

\section{The Moderating Effect of Brand Value of the Main products}

Brand value is a core element in the intangible assets of enterprises (Davcik, Vinhas and Hair, 2015). The higher the brand value is, the more loyal the customers will be. High-value brands usually enjoy price premiums, so that consumers are willing to pay more for these products (Kelly and Lehmann, 2006). Consumers tend to believe that products with high brand value have larger profit margins than those with lower brand value.

Aaker (1991) suggests that, in order to avoid the decline of brand value, famous brands would not bundle themselves with little-known brands in sales promotions. From the view of consumers, the higher the brand value of the promoted products, the stronger the capability of the brands to make profits and afford to offer costly gifts. Hence, the negative effect of gifts' transaction utility will be decreased.

$\mathrm{H} 4 \mathrm{a}$ : The brand value of the promoted products moderates the impacts of free gift promotions on the transaction utility of gifts, which means that the higher the brand value of the promoted products, the smaller the impacts of free gift promotions on the transaction utility of gifts.

Based on the hypotheses of $\mathrm{H} 1, \mathrm{H} 2, \mathrm{H} 3$ and $\mathrm{H} 4 \mathrm{a}$, this paper assumes that, the higher the brand value of the promoted products, the smaller the impacts of free gift promotions on the transaction utility of gift; in this sense, the indirect impacts of free gift promotions on purchase intention of gifts via the mediating effect of transaction utility will thus be decreased.

$\mathrm{H} 4 \mathrm{~b}$ : The brand value of the promoted products moderates the indirect impacts of free gift promotions on purchase intention of gifts via the mediating effect of transaction utility. More specifically, the higher the brand value of the promoted products, the smaller the indirect impacts of free gift promotions on purchase intention of gifts via the mediating effect of transaction utility.

The research model is presented in Figure 1. The interlinking paths in Figure 1 reveal that free gift promotion reduces purchase intention of gifts, and transaction utility of gifts has a mediating effect on the relationship between them. Brand value of main products may weaken the impacts of free gift promotion on transaction utility of gift and moderates the indirect impacts of free gift promotion on purchase intention of gifts via the mediating effect of transaction utility. 


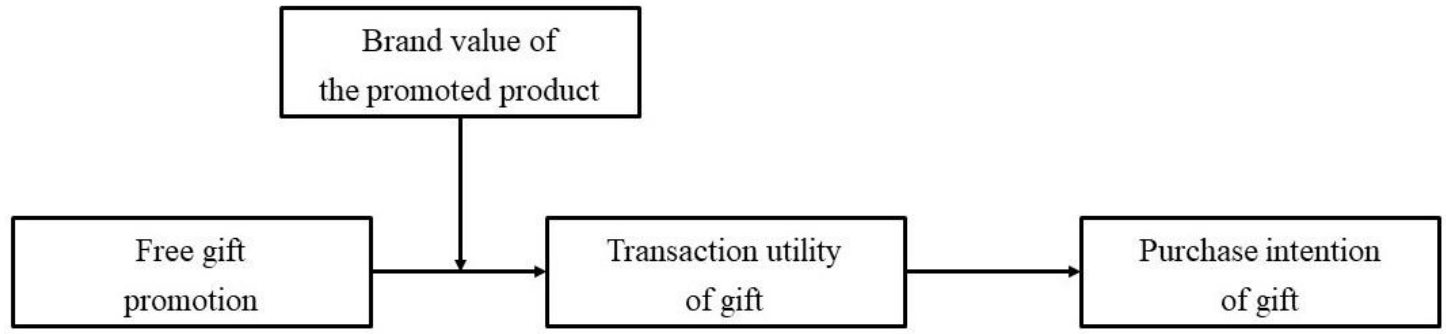

Figure 1 Research Framework

\section{Experiment One}

This experiment is designed to examine the hypotheses of $\mathrm{H} 1, \mathrm{H} 2$, and $\mathrm{H} 3$, namely, to test whether free gift promotions brings down the transaction utility of gifts and purchase intention of gifts, and whether transaction utility has a mediating effect between free gift promotions and purchase intention of gifts.

\section{Research Method and Procedure Experiment Design}

Experiment One employs a between-group design which involves two groups: the experimental group (in which participants are exposed to a free gift promotion) vs. the control group (in which participants are not exposed to any free gift promotion). The participants are randomly allocated to the two groups. The materials used in the experiment are screenshots from JD.com, a famous e-commerce site in China, with a few modifications as needed by the experiment. Based on Kamins, Folkes and Fedorikhin (2009), two groups are asked to view a screenshot of JD.com. For the experimental group, participants are shown a screenshot which suggests that online shoppers on JD.com will be offered a free Logitech mouse with purchase a Lenovo laptop worth RMB 3,599; while participants in the control group are shown an ordinary sales page of the same laptop. In order to make sure that participants have carefully viewed the materials above, they are required to answer two questions: (1) what is the brand of the laptop being sold in the picture? (2) what is the brand of the free mouse (this one is for the experimental group only)? After that, the two groups of participants are told that they can buy the Logitech mouse as a stand-alone product on JD.com at the price of RMB 120. Meanwhile, all of them are required to complete a questionnaire, which is designed to examine how they evaluate the transaction utility of the mouse and their purchase intention of it. According to Rao and Monroe (2002), consumer familiarity with a product or brand significantly influence their evaluation of transaction utility. Hence, this research measured participants' familiarity with mouse products and the Logitech mouse, and then takes these two elements as control variables in the experiment. In addition, the demographic variables (age, gender, education background, and household average monthly income) of participants in two groups are measured as well. Scale

The scale of transaction utility and purchase intention is based on the study of Muehlbacher et al. (2011). The measurement of consumer product familiarity is designed based on Rao and Monroe (2002). Consumers brand familiarity is measured based on Laroche (2003).

\section{Samples}

The samples are obtained from two ways: (1) randomly giving out questionnaires to passers-by in a Higher Education Mega Center; (2) inviting participants to complete online questionnaires by posting message on various BBSs. Every participant is paid one yuan in return. A total of 172 questionnaires are received, which include 129 online questionnaires and 43 print questionnaires. 25 questionnaires are considered to be invalid, as the answers are clearly given in a certain pattern or within a short time or contain several items unanswered. Hence, a total of 147 valid responses are received, reflecting a valid response rate of $85.47 \%$. There are 69 samples in the experimental group and 78 in the control group.

Most participants are in relatively young age groups and from advanced education backgrounds: $92.6 \%$ of participants have received education of junior college or above, and those aged below 35 account for $75.6 \%$ of the total. The experiment materials in this research are electronic products, and highereducated people of relatively young age groups are major customers of these products. The result of chi- 
square test shows that there are no significant differences in the demographics of participants between the two groups.

\section{Experimental Results and Analyses}

The results show that, the Cronbach's a coefficients for transaction utility, purchase intention, consumers product familiarity, and consumers brand familiarity are $0.897,0.916,0.887$ and 0.910 respectively. Hence, the scales are reliable.

In terms of two control variables, there are no significant differences in participants' familiarity with the product (Mexperimental=4.89, Mcontrol=4.91, $\mathrm{P}=0.71$ ) and the brand (Mexperimental=1.76, Mcontrol=1.73, $\mathrm{P}=0.91$ ) between the two groups, which indicates that the control variables will not have a significant effect on experimental results.

The results of Independent $t$-sample test reveals that the experimental group and control group differ significantly on both transaction utility $(\mathrm{F}=27.5, \mathrm{P}<0.01)$ and purchase intention of Logitech mouse $(\mathrm{F}=27.5, \mathrm{P}<0.01)$ (see Table 1). Compared with the experimental group, participants in the control group tend to have a higher evaluation of transaction utility of Logitech mouse, thus showing a stronger purchase intention. Hence, free gift promotions bring down transaction utility and purchase intention of gifts.

Table 1 transaction utility and purchase intention of Logitech mouse

\begin{tabular}{l|c|c}
\hline Group & Transaction utility & Purchase intention \\
\hline Experimental group & 2.58 & 2.585 \\
Control group & 2.98 & 3.047 \\
\hline $\mathrm{F}$ & 27.5 & 32.1 \\
\hline $\mathrm{P}$ & $<0.01$ & $<0.01$ \\
\hline
\end{tabular}

Based on the mediation analysis procedure designed by Zhao, Lynch and Chen (2010) and the Bootstrap method proposed by Preacher and Hayes (2004), a mediation analysis is conducted. In terms of parameters, the sample size is set at 5,000, and the confidence interval is set at $95 \%$. The result of mediation test does not include 0 (LLCI $=-0.0532$, $\mathrm{ULCI}=-0.3372$ ), indicating that transaction utility has a significant mediating effect which is valued at 0.1926 . In addition, when transaction utility is controlled, there is no significant difference in purchase intention of gifts between two groups, and confidence interval (LLCI $=-0.0579$, ULCI $=0.1352$ ) includes 0. Hence, transaction utility has a complete mediating effect on the impacts of free gift promotions on purchase intention of gifts.

\section{Discussion}

The results in Experiment One show that, free gift promotions bring down purchase intention of gifts, which is similar to the findings of Kamins, Folkes and Fedorikhin (2009)and Raghubir (2004).The study also shows that transaction utility has a complete mediating effect on the relationship between free gift promotions and purchase intention of gifts. Therefore, the hypotheses of $\mathrm{H} 1, \mathrm{H} 2$, and $\mathrm{H} 3$ are valid. Next, experiment two is designed to examine the hypotheses of $\mathrm{H} 4 \mathrm{a}$ and $\mathrm{H} 4 \mathrm{~b}$, which is a moderated mediation test.

\section{Experiment Two}

\section{Pre-experimental Design}

The aim of the pre-experimental design is to determine the influence of brand value of the promoted products. Based on the experiment conducted by Park (2009), this research deems the real brand Lenovo as the high-value one, and the virtual brand Dreamer as the low-value one. According to Interbrand, the world's biggest brand consultancy, Lenovo ranked 100th in its 2015 Best Global Brands Report, indicating a relatively high brand value; while Dreamer is a virtual brand, so its brand value is assumed to be comparatively low. Questionnaires are used to test the brand value of Lenovo and Dreamer. The scale for measuring brand value is borrowed from Lassar, Mittal and Sharma (1998). Through convenience sampling, this research selects 70 students from a university and receives 68 valid questionnaires. It turns out that the Cronbach's a coefficient is 0.965 , indicating a decent reliability. The 
paired sample t-test shows that the brand value of Lenovo is significantly higher than that of Dreamer $\left(\mathrm{M}_{\text {Lenovo }}=3.27, \mathrm{M}_{\text {Dreamer }}=2.17, \mathrm{P}<0.01\right)$.

\section{Research Method and Procedure Experiment Design}

The design in Experiment Two is a 2 (free gift promotion: with/without) $\times 2$ (brand value of the promoted product: high/low) between-group design. Participants are randomly allocated to the four groups. Same as Experiment One, the materials used in the experiment are screenshots from JD.com and are shown to participants before the beginning of the experiment. For the group of "with free gift promotion + high brand value", participants are shown a screenshot which suggests that online shoppers on JD.com will be offered a free Logitech Mouse with purchase a Lenovo laptop worth RMB 3,599. The group of "with free gift promotion + low brand value" is asked to view a screenshot which suggests that online shoppers on JD.com will be offered a free Logitech Mouse with purchase a Dreamer laptop worth RMB 3,599. Participants in the group of "without free gift promotion + high brand value" are shown an ordinary page selling the Lenovo laptop as a stand-alone product. The group of "without free gift promotion + low brand value" is shown an ordinary sales page of the same Dreamer laptop. After that, participants are told that they can buy the Logitech mouse as a stand-alone product on JD.com at the price of RMB 120. This research then examines transaction utility of the mouse, purchase intention, and how familiar they are with mouse products and the Logitech brand. The demographic variables (age, gender, education background, and household average monthly income) of participants in four groups are measured as well. The scales for measuring transaction utility, purchase intention, and consumers' familiarity with product and brand are the same as those in Experiment One.

\section{Samples}

Participants are obtained from two ways: (1) 157 first-year students from the business school and engineering school of a university are recruited to participate in the experiment; (2) inviting participants to complete online questionnaires by posting message on various BBSs, such as Baidu Tieba. Every respondent is paid one yuan in return.

A total of 267 questionnaires are received, which include 110 online questionnaires and 157 print questionnaires. Among them, 28 questionnaires are considered to be invalid. As a result, a total of 239 valid responses are received, reflecting a valid response rate of $89.5 \%$. There are 61 valid responses from the group of "with free gift promotion + high brand value", 57 from the group of "with free gift promotion + low brand value", 59 from the group of "without free gift promotion + high brand value", and 62 from the group of "without free gift promotion + low brand value".

On the whole, there are similar percentages of male and female participants involved in the experiment, with males accounting for $53.6 \%$. Participants who have received education of college account for $77 \%$, and participants aged below 35 account for $83.7 \% .88 .7 \%$ of participants have a household average monthly income of no more than RMB 4,500. The chi-square test shows that there are no significant differences in the demographics of participants between the four groups.

As in Experiment One, most participants in Experiment Two are of relatively young age groups and from advanced education backgrounds. These people are major customers of electronic products.

\section{Experimental Results and Analyses}

The results show that, the Cronbach's a coefficients for transaction utility, purchase intention, consumers product familiarity, and consumers brand familiarity are $0.835,0.808,0.890$ and 0.902 respectively. Hence, the scales are reliable.

There are no significant differences in participants' familiarity with the product $\left(\mathrm{M}_{\text {with+high }}=3.20\right.$, $\left.\mathrm{M}_{\text {without+high }}=3.17, \mathrm{M}_{\text {with+low }}=3.22, \mathrm{M}_{\text {without+low }}=3.25, \mathrm{P}=0.88\right)$ and brand $\left(\mathrm{M}_{\text {with+high }}=1.87, \mathrm{M}_{\text {without+high }}=1.82\right.$, $\mathrm{M}_{\text {with+low }}=1.77, \mathrm{M}_{\text {without+low }}=1.79, \mathrm{P}=0.72$ ) between the four groups, which indicates that two control variables will not have a significant effect on experimental results.

By taking free gift promotion and the brand value of the promoted products as the fixed factors and transaction utility of gifts as the dependent variable, multifactor analysis of variance is conducted. The results show that free gift promotions have a significant main effect on transaction utility of gifts $(\mathrm{F}=7.2$, $\mathrm{P}<0.05)$, which further confirms the hypothesis of $\mathrm{H} 1$ that free gift promotions decrease transaction utility 
of gifts. Meanwhile, the interaction term of two fixed factors significantly influence transaction utility of gifts $(\mathrm{F}=6.9, \mathrm{P}<0.05)$, suggesting that brand value of the main products moderates the impacts of free gift promotions on the transaction utility of gifts. Through a further analysis of simple effect, it is revealed that when brand value of the main products is relatively high, free gift promotions undermine transaction utility of gifts $\left(\mathrm{M}_{\text {without }}=3.08, \mathrm{M}_{\text {with }}=2.77, \mathrm{P}<0.05\right)$. When brand value of the main products is comparatively low, free gift promotions also decrease transaction utility of gifts $\left(\mathrm{M}_{\text {without }}=2.94, \mathrm{M}_{\text {with }}=2.05, \mathrm{P}<0.05\right)$, and the drop in the latter condition is sharper than that in the former one $(\mathrm{P}<0.05)$. Therefore, the higher brand value of the main products, the smaller the impacts of free gift promotions on transaction utility of gifts (See Graph 2). The hypothesis of H4a is valid.

Based on the analysis procedure proposed by Zhao, Lynch and Chen (2010) and the moderated mediation model (model 8) proposed by Preacher and Hayes (2007), a Bootstrap mediation analysis is conducted. In terms of parameters, the sample size is set at 5,000, and the confidence interval is set at $95 \%$. The results show that, for the impacts of the interaction term of two fixed factors (free gift promotion and brand value of the promoted product) on purchase intention of gifts, transaction utility has a mediating effect which is valued at -0.4875 . Bootstrap confidence interval (LLCI $=0.2521$, ULCI $=0.7484$ ) does not include 0 . More specifically, when brand value of the promoted products is relatively high, transaction utility has a significant mediating effect which is valued at -0.26 , and Bootstrap confidence interval (LLCI=-0.4484, $\mathrm{ULCI}=-0.0591$ ) does not include 0 . When brand value of the promoted products is low, transaction utility still has an obvious mediating effect which is valued at -0.75 , and Bootstrap confidence interval (LLCI=-0.9101, $\mathrm{ULCI}=-0.6106$ ) does not include 0 either. Moreover, there are significant differences between the mediating effects in the two conditions $(\mathrm{P}<0.05)$. Hence, brand value of the main products moderates the indirect impacts of free gift promotions on purchase intention of gifts via the mediating effect of transaction utility. In other words, the higher brand value of the main products, the smaller the indirect impacts of free gift promotions on purchase intention of gifts via the mediating effect of transaction utility. Therefore, the hypothesis of $\mathrm{H} 4 \mathrm{~b}$ is valid.

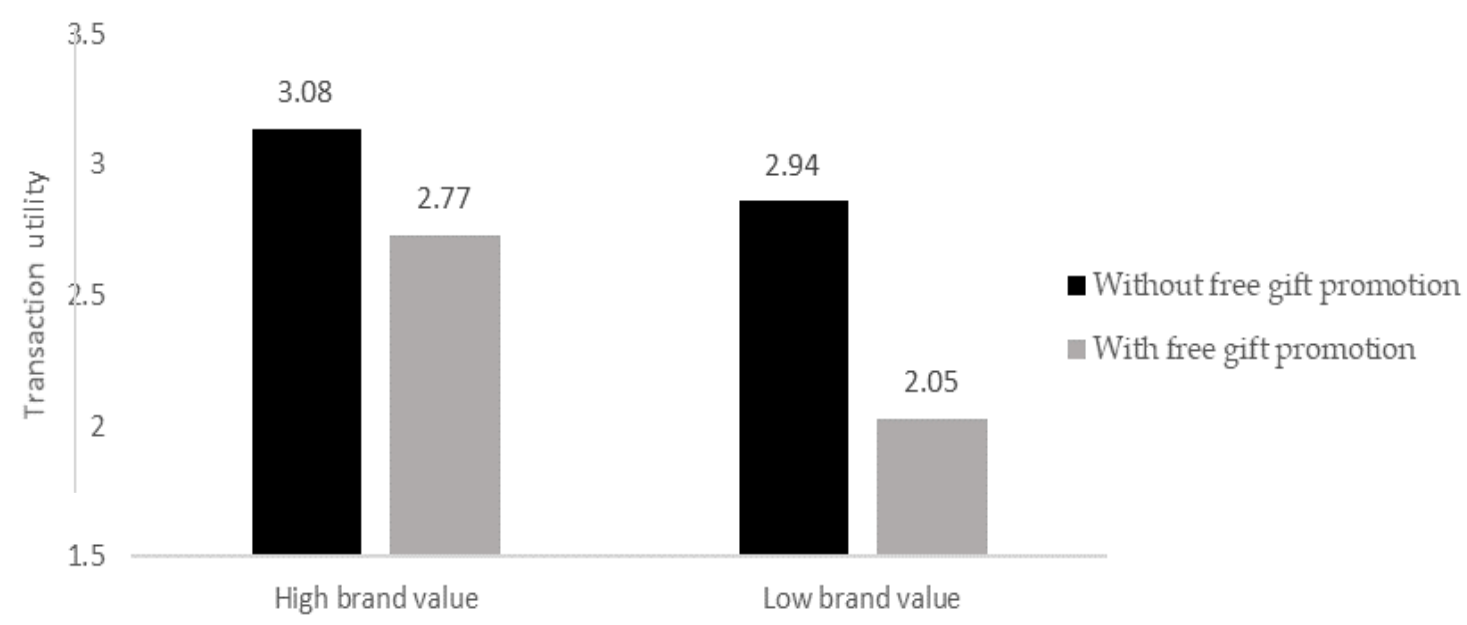

Figure 2 The moderating effect of the brand value of the promoted product

\section{Discussion}

According to Raghubir (2004), the value-discounting effect of gifts is weaker when they are offered along with purchase of higher-priced main products as compared to lower-priced ones. In experimental two, the results show that brand value of the main products moderates the impacts of free gift promotions on the transaction utility of gifts. The results also indicate that brand value of the main products moderates the indirect impacts of free gift promotions on purchase intention of gifts via the mediating effect of transaction utility. The hypotheses of $\mathrm{H} 4 \mathrm{a}$ and $\mathrm{H} 4 \mathrm{~b}$ are valid. 


\section{Conclusions and Future Research}

Previous research has mainly concentrated on the impacts of free gift promotions on the main products. The result of this research shows that, free gift promotions also reduce purchase intention of gifts. Raghubir (2004) first proposes the theory of value-discounting effect in free gift promotions. He argues that free gifts promotions lower prices that consumers are willing to pay for the gifts (Raghubir, 2004). Based on transaction utility theory, this research explores the mechanism of the impacts of free gift promotions on purchase intention of gifts. It is found that free gift promotions decrease transaction utility of the gifts which, on the other hand, has a complete mediating effect on the relationship between free gift promotions and purchase intention of gifts. In addition, brand value of the main products significantly moderates the impacts of free gift promotions on transaction utility of gifts: the higher brand value of the main products, the smaller the negative impacts of free gift promotions on transaction utility. Brand value of the main products also significantly moderate the indirect impacts of free gift promotions on purchase intention of gifts via the mediating effect of gifts' transaction utility: the higher brand value of the main products, the smaller the indirect impacts. By profoundly discussing the internal mechanism of how free gift promotions impact purchase intention of gifts, this research has made contributions to improving the theoretical system of free gift promotion.

As market competition is increasingly fierce, manufacturers and retailers are giving away branded products as gifts in free gift promotions, so as to appeal to more consumers. According to the results in this research, although free gifts promotion may raise the sales of main products, but it may decrease the sales of gifts as well when the gifts are sold as stand-alone products. When launching free gift promotions, retailers and manufacturers need to be cautious to use branded products as free gifts. The relationship between the sales of the main products and gifts products should be balanced, especially when the gifts are branded products with decent sales. Retailers and manufacturers shall carefully think over the options which can be offered as free gifts with purchase of the main products. If the brand value of the main products is relatively low, enterprises shall not offer high-quality branded products as free gifts, as the main products may negatively affect the brand value of gifts.

There are some limitations in this study. Firstly, most participants in this research are college students. The external validity of the research is somewhat undermined. The future research is needed, on a larger scale, to choose diversified samples. Secondly, famous laptop and mouse brand are chosen as the materials. These products are relatively costly, which may lead to high consumer involvement. It remains to be explored whether free gift promotions negatively impact purchase intention of gifts in the case of low-involvement products. Thirdly, this research focuses on the moderating effect of brand value of the main products. It is yet to be explored if the gift combination (either two complementary products or two substitute products) moderate the impacts of free gift promotions on purchase intention of gifts.

\section{References}

Aaker, David A. (1991). Managing Brand Equity: Capitalizing on the Value of the Brand Name, New York: Free Press.

Chandon P., Wansink B., Laurent G. (2000). A Benefit Congruency Framework of Sales Promotion Effectiveness [J]. Journal of marketing, 64(4): 65-81

Davcik N. S., Vinhas D. S. R., Hair J. F. (2015). Towards a Unified Theory of Brand Equity: Conceptualizations, Taxonomy and Avenues for Future Research [J]. Journal of Product \& Brand Management, 24(1): 3-17

Fan X. C. (2000). Analysis of Brand Equity and Its Measurement [J]. Nankai Business Review, 3(1) : 9-15

Folkes V., Wheat R. D. (2013). Consumers' Price Perceptions of Main products [J]. Journal of Retailing, 71(3): $317-328$

Gilbert D. C., Jackaria N. (2002). The Efficacy of Sales Promotions in UK Supermarkets: A Consumer View [J]. International Journal of Retail \& Distribution Management, 30(6): 315-322

Harlam B. A., Lodish L. M. (2012). Modeling Consumers' Choices of Multiple Items [J]. Journal of Marketing Research, 32(4): 404-418

Inman J. J., Mcalister L., Hoyer W. D. (1990). Promotion Signal: Proxy for a Price Cut? [J]. Journal of Consumer Research, 17(1): 74-81

Kalyanaram G., Little J. D. (1994). An Empirical Analysis of Latitude of Price Acceptance in Consumer Package Goods [J]. Journal of Consumer Research, 21(3): 408-418

Kalyanaram G., Winer R. S. (1995). Empirical Generalizations from Reference Price Research [J]. Marketing Science, 14(3): 161-169

Kalwani M. U., Morrison D. G., Chi K. Y. (2014). Consumer Price and Promotion Expectations: An Experimental Study [J]. Journal of Marketing Research, 29: 90-100 
Kamins M. A., Folkes V. S., Fedorikhin A. (2009). Promotional Bundles and Consumers' Price Judgments: When the Best Things in Life Are Not Free [J]. Journal of Consumer Research, 36(4): 660-670

Keller K. L. (1993). Conceptualizing, Measuring and Clustered-based Brand Equity [J]. Journal of Marketing, 57: 1-29

Keller K. L., Lehmann D. R. (2006). Brands and Branding: Research Findings and Future Priorities [J]. Marketing Science, 25(6): 740-759

Lai Hsiangchu, Her-Sen Doong and Chen-Yuan Yang. The Effect of Price Dispersion in an e-Market on Consumers' Intentions to Join Group Buying. Proceedings of the 39th Hawaii International Conference on System Sciences - 2006

Laroche M., Pons F., Zgolli N., et al. (2003). A Model of Consumer Response to Two Retail Sales Promotion Techniques [J]. Journal of Business Research, 56(7): 513-522

Lassar W., Mittal B., Sharma A. (1998). Measuring Customer-based Brand Equity [J]. Journal of Consumer Marketing, 12(4): 11-19

Mccarthy M. S., Norris D. G. (1999). Improving Competitive Position Using Branded Ingredients [J]. Journal of Product $\mathcal{E}$ Brand Management, 8(4): 267-285

Muehlbacher S., Kirchler E., Kunz A., et al. (2011). The Impact of Transaction Utility on Consumer Decisions [J]. Journal of Psychology, 219(4): 217-223

Park H. (2009). Affecting Variables on Brand Preference and Performance of Domestic and Imported Cosmetics Brands [J]. Korean Journal of Human Ecology, 18(2): 523-534

Preacher K. J., Hayes A. F. (2004). SPSS and SAS Procedures for Estimating Indirect Effects in Simple Mediation Models [J]. Behavior Research Methods, Instruments, \& Computers, 36(4): 717-731

Raghubir P. (2004). Free Gift with Purchase: Promoting or Discounting the Brand? [J]. Journal of Consumer Psychology, 14(1): 181-186

Rao A. R., Monroe K. B. (1988). The Moderating Effect of Prior Knowledge on Cue Utilization in Product Evaluations [J]. Journal of Consumer Research, 15: 253-264

Thaler R. (1985). Mental Accounting and Consumer Choice [J]. Marketing Science, 4(3): 199-214

Urbany J F, Ycardcn W. O., and Wcilbaker D. C. (1988). The effects of plausible and exaggerated reference pricing on consumer perceptions and price search [J]. Journal of Consumer Research, 15(1): 95-110

Winer R. S. A. (2007). Reference Price Model of Brand Choice for Frequently Purchased Products [J]. Journal of Consumer Research, 25(6): 250-256

Zhang Z. Z., Xie Q. Z. (2015). The Effects of Product Information, Reference Prices and Perceived Quality on Consumers' Behavioral Intentions [J]. Journal of Business Administration (Taiwan), 47: 161-190

Zhao X., Lynch J. G., Chen Q. (2010). Reconsidering Baron and Kenny: Myths and Truths about Mediation Analysis [J]. Journal of Consumer Research, 37(2): 197-206 